\title{
Vitamin D deficiency and risk of acute lung injury in severe sepsis and severe trauma: a case-control study
}

\author{
Nicolas Barnett ${ }^{1}$, Zhiguo Zhao ${ }^{2}$, Tatsuki Koyama², David R Janz ${ }^{1}$, Chen-Yu Wang ${ }^{1,4}$, Addison K May ${ }^{3}$, \\ Gordon R Bernard ${ }^{1}$ and Lorraine B Ware ${ }^{1,5^{*}}$
}

\begin{abstract}
Background: The aim of this study was to determine the association between 25 -hydroxyvitamin D (25-OHD) levels at the onset of critical illness and the development of acute lung injury/acute respiratory distress syndrome (ALI/ARDS) in patients with sepsis or trauma.

Methods: We performed two nested case-control studies of 478 patients with sepsis and trauma with or without ALI/ARDS admitted to the medical, surgical and trauma ICUs of a tertiary-care center. Cases consisted of patients with either sepsis or trauma and ALI/ARDS; controls consisted of equivalent numbers of matched patients with either sepsis or trauma alone. We measured serum 25-OHD levels the morning after ICU admission and used multivariable regression to assess the relationship between 25-OHD and diagnosis of ALI/ARDS during the first four ICU days, controlling for age, gender, diabetes, smoking status and season.
\end{abstract}

Results: 25-OHD levels did not differ between cases with ALI/ARDS and controls in either the sepsis or trauma cohorts. Using a conditional logistic regression model, sepsis patients during the winter season with higher 25-OHD levels were more likely to develop acute lung injury (odds ratio 1.68, 95\% confidence interval of 1.05 to 2.69 , $P=0.03$ ). This association did not hold for the trauma cohort in either season. Sepsis and trauma patients had a lower risk of hospital mortality at higher 25-OHD levels but neither relationship reached significance. Higher one-year mortality after trauma was associated with lower 25-OHD levels ( $H R$ 0.50, $\mathrm{Cl} 0.35,0.72 P=0.001$ ).

Conclusions: Serum 25-OHD measured early after admission to intensive care is not associated with the development of acute lung injury, hospital or one-year mortality in critically ill patients with sepsis although lower 25-OHD levels were associated with higher one-year mortality in patients with severe trauma.

Keywords: Vitamin D; Sepsis; Trauma; Acute lung injury; Critical illness

\section{Background}

Epidemiologic and biologic evidence supports a pivotal role for vitamin D in health and disease [1-9]. Serum vitamin D levels (as reflected by the serum concentration of $25-\mathrm{OHD})$ in the lowest quartile $(<45 \mathrm{nmol} / \mathrm{L})$ are associated with excess all-cause mortality in the general population. In a meta-analysis of randomized controlled trials in

\footnotetext{
* Correspondence: Lorraine.ware@vanderbilt.edu

'Division of Allergy, Pulmonary and Critical Care Medicine in the Department of Medicine, Vanderbilt University, T1218 MCN, 1161 21st Avenue South, Nashville, TN, USA

${ }^{5}$ Department of Pathology, Microbiology and Immunology, Vanderbilt University, Nashville, TN, USA

Full list of author information is available at the end of the article
}

which vitamin D was administered for any health condition, supplementation with standard doses reduced overall mortality [10], an observation substantiated by a recent Cochrane review [11]. Biologic data reinforce these observations [9]. Specifically, vitamin D and its receptor exhibit key anti-inflammatory [12], membrane-stabilizing [13] and anti-microbial properties [14] at barrier sites such as the gut [15], lung [16] and skin [17].

In critical illness, vitamin $\mathrm{D}$ deficiency is prevalent, $[18,19]$ has been associated with increased length of ICU stay [20] and adverse outcomes [21]. Low 25-OHD levels measured within the year prior to intensive care admission [22] but also at critical care initiation [23] are significantly 
associated with increased short and long term mortality. Acute lung injury (ALI) and acute respiratory distress syndrome (ARDS) are syndromes of acute respiratory failure occurring in the setting of common clinical conditions including sepsis and trauma. It is still not understood why some but not all patients at risk develop ALI/ARDS [24]. Several features of the pathogenesis of ARDS, including the central role of innate immunity, inflammation and the presence of increased lung endothelial and epithelial permeability [25], suggest a candidate role for vitamin $\mathrm{D}$ in modulating its development. Vitamin D's anti-inflammatory properties [26], pervasive role in endothelial [27] and epithelial barrier functions [16] and potential to augment innate immunity [14] make it an important avenue to explore in the pathogenesis of ALI.

We hypothesized that lower 25-OHD levels at the onset of critical illness would be associated with the development of ALI/ARDS in two distinct populations at high risk for ALI/ARDS: patients with severe sepsis and patients with severe trauma. To test this hypothesis we measured serum 25-OHD levels early in the course of critical illness in two nested, parallel, case-control studies: patients with severe sepsis with or without ALI/ ARDS; and patients with severe trauma with or without ALI/ARDS.

\section{Methods}

\section{Study design and patients}

Cases and controls were selected from the Validating Acute Lung Injury biomarkers for diagnosis (VALID) study. VALID is a single-center 2,500 patient observational cohort study of critically ill patients at high-risk for ALI/ARDS [28,29], enrolling since 2006. Patients were recruited from medical, surgical, cardiac and trauma ICUs at Vanderbilt University Medical Center. All ICU patients mechanically ventilated $>12$ hours were eligible for enrollment. Patients were excluded if they were $<18$ years of age, were in any other ICU for > three days, had cardiac arrest before enrollment, or if they were expected to be transferred out of ICU by day two. Patients were also excluded if they were admitted for an uncomplicated overdose, routine postoperative admission after cardiothoracic surgery or if they had a history of severe chronic lung disease. Comprehensive clinical data were obtained including the Acute Physiology and Chronic Health Evaluation II (APACHE II) score [30], Injury Severity Score (ISS) [31], daily phenotyping for sepsis [32], organ failure [33] and ALI/ARDS using the American European Consensus Conference definitions [34]. Severe trauma was defined as an ISS score > 15. Non-pulmonary organ failures were assessed by Brussels scoring [33]. Informed consent was obtained from an available surrogate or the participants themselves when possible. A waiver of consent was also granted due to the minimal risk for study participants. The Institutional Review Board at Vanderbilt approved the study protocol.

For the sepsis study, cases were defined as patients with severe sepsis at the time of enrollment meeting consensus criteria for ALI/ARDS during the first four days in the ICU after enrollment. Controls were patients with severe sepsis at the time of enrollment not meeting consensus criteria for ALI/ARDS during the first four days in the ICU. For the trauma study, cases were defined as patients with severe trauma who met consensus criteria for ALI/ARDS during the first four days in the ICU. Controls were patients with severe trauma who did not meet consensus criteria for ALI/ARDS during the first four days in the ICU. In both studies, controls were matched one to one to cases for severity of illness using the APACHE II for the sepsis cohort and the ISS for the trauma cohort. Cases and controls were also matched for age (within five years), length of daylight at enrollment (within one hour) and ethnicity - all factors that may affect 25-OHD levels [35]. We identified 480 suitable patients from VALID: 120 cases with ALI/ARDS and sepsis, 120 cases with ALI/ARDS and trauma and a matching number of sepsis (120) and trauma (120) controls. One patient from the trauma cohort had no serum its matched pair was therefore removed leaving a total of 478 eligible patients (119 trauma cases and 119 trauma controls). Of these, one trauma patient and one sepsis patient did not have sufficient serum for vitamin $\mathrm{D}$ analysis (see Additional file 1).

\section{Vitamin D measurement}

Samples were obtained the morning after ICU admission, processed within one hour of collection, centrifuged and stored at $-80^{\circ} \mathrm{C}$ until further analysis. For quantitative determination of 25-OHD we used a Food and Drugs Administration approved [35], direct, competitive chemiluminescence immunoassay (CLIA) using the DiaSorin LIASON 25-OHD total assay (Heartland Assays, Ames, IA, USA) [36]. Serum 25-OHD was measured in duplicate.

\section{Definition of deficiency}

Sufficiency was defined as 25-OHD > $75 \mathrm{nmol} / \mathrm{L}$, insufficiency 50 to $75 \mathrm{nmol} / \mathrm{L}$ and deficiency < $50 \mathrm{nmol} / \mathrm{L}$ [37].

\section{Exposure, covariates and outcomes}

The primary exposure variable was the serum 25-OHD level measured on the morning of ICU day two. Multiple covariates were selected a priori including age, gender, diabetes, smoking status and season for their potential confounding effects on risk of ALI and modulation of vitamin D levels. Levels of 25-OHD in the tables are presented in $\mathrm{nmol} / \mathrm{L}$. 
The primary outcome was development of ALI/ARDS in the first four days of admission to the ICU, which was the time frame for intensive clinical phenotyping for ALI/ARDS in the VALID study. Hospital mortality and all-cause one-year mortality were pre-specified secondary end-points.

\section{Statistical analysis}

We fit multivariable conditional logistic regression models using $\log$ transformed 25-OHD to investigate the effects of 25-OHD on our primary and secondary outcomes. Pre-specified exploratory variables included age, gender, smoking status, diabetes and season. As an additional analysis, we a priori stratified patients into two seasons, a summer season (21 June to $21 \mathrm{Dec}$ ) and a winter season (21 Dec to 21 June) and thus included an interaction term for season in our model to investigate the season-specific effects on our primary outcome of interest (ALI/ARDS).

We used Cox proportional hazard models to investigate the effects of 25-OHD on the secondary outcomes hospital mortality and one-year mortality. In the trauma cohort, ISS was missing for 34 subjects. A multiple imputation method with ten imputation datasets was used to accurately estimate the parameters and standard errors of risk factors. All statistical inferences were assessed at a two-sided 5\% significant level. All summary statistics, graphics, and models were generated using $\mathrm{R}$ version 2.13.1 statistical software.

Table 1 Baseline characteristics of patients from the sepsis cohort

\begin{tabular}{|c|c|c|c|c|c|}
\hline Characteristic & $N$ & $\begin{array}{l}\text { Cases } \\
(n=120)\end{array}$ & $\begin{array}{l}\text { Controls } \\
(n=120)\end{array}$ & $\begin{array}{l}\text { Combined } \\
(n=240)\end{array}$ & $P$-value \\
\hline $\operatorname{Age}^{c}(\mathrm{IQR})$ & 240 & $59.3(53.2,65.7)$ & $59.3(52.7,65.7)$ & $59.3(53.2,65.7)$ & $0.885^{\mathrm{a}}$ \\
\hline Female gender (\%) & 240 & $53(44)$ & $56(47)$ & $109(45)$ & $0.791^{b}$ \\
\hline Smoking (\%) & 231 & & & & $0.505^{b}$ \\
\hline Never & & $40(34)$ & $33(29)$ & $73(32)$ & \\
\hline Former & & $44(38)$ & $40(35)$ & $84(36)$ & \\
\hline Current & & $33(28)$ & $41(36)$ & $74(32)$ & \\
\hline Diabetes (\%) & 240 & $31(26)$ & $47(39)$ & $78(32)$ & $0.045^{b}$ \\
\hline Summer season (\%) & 240 & $34(28)$ & $35(29)$ & $69(29)$ & $1^{\mathrm{b}}$ \\
\hline Day length hours $(\mathrm{IQR})^{\mathrm{c}}$ & 240 & $12.0(10.6,13.6)$ & $12.0(10.6,13.5)$ & $12.0(10.6,13.6)$ & $0.655^{\mathrm{a}}$ \\
\hline$\overline{\text { APACHE } \| \text { Score }(\mathrm{IQR})^{c}}$ & 240 & $28(23,32.2)$ & $28(23,32.2)$ & $28(23,32.2)$ & NA \\
\hline Number of non-pulmonary organ failures (\%) & 240 & & & & $0.753^{\mathrm{a}}$ \\
\hline 0 & & $15(12)$ & $24(20)$ & $39(16)$ & \\
\hline 1 & & $60(50)$ & $45(38)$ & $105(44)$ & \\
\hline 2 & & $39(32)$ & $39(32)$ & $78(32)$ & \\
\hline 3 & & $4(3)$ & 9 (8) & $13(5)$ & \\
\hline 4 & & $2(2)$ & $3(2)$ & $5(2)$ & \\
\hline Days of ICU stay (IQR) & 240 & $9(6,15)$ & $6(4,10)$ & $7(4,14)$ & $0.008^{\mathrm{a}}$ \\
\hline Hospital mortality (\%) & 240 & $30(25)$ & $31(26)$ & $61(25)$ & $1^{\mathrm{b}}$ \\
\hline One-year mortality (\%) & 240 & $66(55)$ & $71(59)$ & $137(57)$ & $0.614^{\mathrm{b}}$ \\
\hline Risk factors for ALI/ARDS & 240 & & & & $<0.001^{\mathrm{b}}$ \\
\hline Non-pulmonary sepsis & & $55(46)$ & $70(60)$ & $125(53)$ & \\
\hline Pneumonia & & $39(33)$ & $22(19)$ & $61(26)$ & \\
\hline Aspiration & & $24(20)$ & $8(7)$ & $32(14)$ & \\
\hline Other or None ${ }^{d}$ & & $1(1)$ & $16(14)$ & $17(16)$ & \\
\hline Patients on ventilator & & 89 (74) & $71(59)$ & $160(67)$ & $0.016^{\mathrm{b}}$ \\
\hline $25-\mathrm{OHD}(\mathrm{nmol} / \mathrm{L})(\mathrm{IQR})$ & 239 & $45.8(29.9,60.8)$ & $39.0(25.0,56.9)$ & $43.2(27.6,58.8)$ & $0.123^{a}$ \\
\hline Vitamin D status (\%) & 239 & & & & $0.358^{\mathrm{b}}$ \\
\hline Deficiency $(<50 \mathrm{nmol} / \mathrm{L})$ & & $72(60)$ & $82(69)$ & $154(64)$ & \\
\hline Insufficiency (50 to $75 \mathrm{nmol} / \mathrm{L}$ ) & & $32(27)$ & $26(22)$ & $58(24)$ & \\
\hline Sufficiency (> $75 \mathrm{nmol} / \mathrm{L})$ & & $16(13)$ & $11(9)$ & $27(11)$ & \\
\hline
\end{tabular}

Data given as median with interquartile range (IQR) or frequency with (\%) of patients.

$\mathrm{N}$ is the number of non-missing values.

${ }^{a}$ Wilcoxon signed rank test; ${ }^{b}$ McNemar's test; ${ }^{c}$ Matched; ${ }^{d}$ Other or None (pancreatitis, multiple transfusions, trauma). 
In the absence of pilot data, we relied on published data in determining appropriate sample size for this study $[19,38]$. Based on a reconstructed distribution with mean 35 to $38 \mathrm{nmol} / \mathrm{L}$ and a standard deviation of approximately 22, a sample of size of 240 (120 cases and 120 controls) has a power of $90 \%$ (with type I error rate of $5 \%$ ) to detect a difference equivalent to approximately $40 \%$ to $50 \%$ of a within-group standard deviation using a simple $t$-test. Additionally, with a total sample size of approximately 240 for each cohort, we included five variables in our multivariable model without risk of over-fitting. To determine the association of 25-OHD levels with our primary (ALI/ARDS) and secondary (hospital and one-year mortality) outcomes in our regression models, we opted to compare 25-OHD levels at fixed points on a continuous scale: third (upper) and first (lower) quartiles.

\section{Results}

\section{Sepsis cohort}

Patient characteristics and vitamin D status are summarized in Table 1. Cases and controls were well matched for baseline characteristics but differed on other important characteristics such as presence of diabetes, use of minute ventilation and risk factors for ALI/ARDS (Table 1). Eightyeight percent of patients with severe sepsis had vitamin D deficiency or insufficiency (serum 25-OHD $<75 \mathrm{nmol} / \mathrm{L}$ ). Median serum 25-OHD concentration was $43.2 \mathrm{nmol} / \mathrm{L}$. There was no significant difference in serum 25-OHD levels between ALI cases and controls (median 45.8 versus $39.0 \mathrm{nmol} / \mathrm{L}, P=0.12$ ) (Table 1 and Figure 1 ).

A higher serum level of 25-OHD in patients admitted during winter months was associated with developing ALI/ARDS; odds ratio (OR) was 1.68 (95\% CI 1.054 to
2.69), $(P=0.03)$ for the upper $(58.3 \mathrm{nmol} / \mathrm{L})$ compared to the lower quartile $(27.6 \mathrm{nmol} / \mathrm{L})$. During summer months we observed no association between 25-OHD levels and development of ALI/ARDS; OR 1.16 (95\% CI 0.589 to 2.25$),(P=0.66)$ (Table 2 and Figure 2$)$.

When all patients with severe sepsis were considered together (both cases and controls) patients with 25OHD levels at the highest quartile $(58.3 \mathrm{nmol} / \mathrm{L})$ had a hazard ratio of 0.74 (95\% CI 0.53 to 1.05 ) for hospital mortality compared to the lowest quartile $(27.6 \mathrm{nmol} / \mathrm{L})$, a result that was not significant $(P=0.09)$ (Table 3$)$. Patient survival time up to one year was also not associated with 25-OHD levels $(P=0.24)$ (Table 4$)$.

\section{Trauma cohort}

Trauma patient characteristics are summarized in Table 5. The trauma cohort was well matched for baseline and secondary characteristics. The median serum 25-OHD level in trauma patients was $53.4 \mathrm{nmol} / \mathrm{L}$. Eighty-one percent of trauma patients were either vitamin D insufficient or deficient. There was no significant difference in serum 25OHD levels between trauma ALI and non-ALI groups (54.9 versus $50.8 \mathrm{nmol} / \mathrm{L}, P=0.30$ ) (Figure 1 ) nor was any statistically significant relationship detected on multivariable analysis (Table 2 and Figure 3).

In the trauma cohort, 25-OHD levels were also not significantly associated with time to hospital mortality - hazard ratio 0.59 (95\% CI 0.3 to 1.20$),(P=0.14)$ (Table 3$)$. On the other hand, 25-OHD levels significantly predicted all-cause, one-year mortality from trauma $(P=0.001)$, hazard ratio 0.5 (95\% CI 0.35 to 0.72 ) (Table 4.) Age was also significantly associated with hospital and all-cause mortality from trauma with hazard ratios of 1.07 (95\% CI

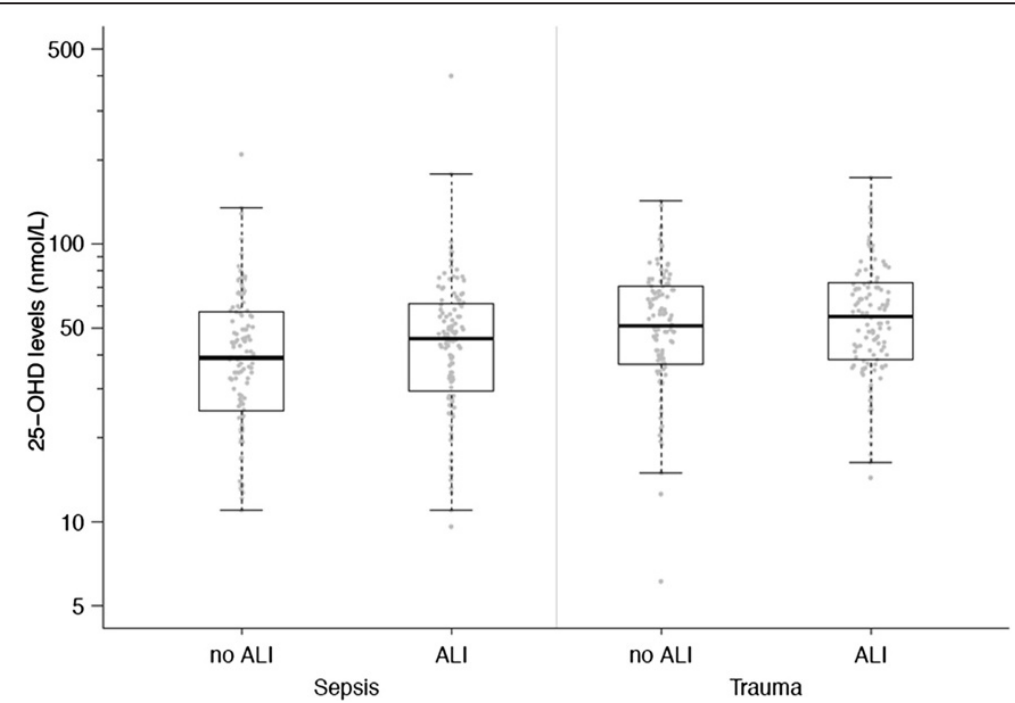

Figure 1 Box plot summary of $\mathbf{2 5}$-hydroxyvitamin D (25-OHD) levels by cohort and case-control status. Twenty-five-OHD levels were not significantly different between patients with or without acute lung injury/acute respiratory distress syndrome (ALI/ARDS). Horizontal bars represent medians, boxes encompass the $25^{\text {th }}$ to $75^{\text {th }}$ percentile and error bars encompass the $10^{\text {th }}$ to $90^{\text {th }}$ percentile. 
Table 2 Conditional logistic regression analysis for risk of acute lung injury/acute respiratory distress syndrome (ALI/ARDS) in the sepsis cohort (left) and trauma cohort (right)

\begin{tabular}{|c|c|c|c|c|c|c|}
\hline \multirow[t]{2}{*}{ Characteristics } & \multicolumn{3}{|c|}{ Sepsis cohort } & \multicolumn{3}{|c|}{ Trauma cohort } \\
\hline & $\overline{\mathrm{OR}}$ & $95 \% \mathrm{Cl}$ & $P$-value & $\overline{O R}$ & $95 \% \mathrm{Cl}$ & $P$-value \\
\hline Age (increment of one year) & 0.98 & 0.84 to 1.15 & 0.805 & 0.93 & 0.77 to 1.13 & 0.482 \\
\hline Gender (male versus female) & 1.14 & 0.63 to 2.04 & 0.668 & 0.81 & 0.39 to 1.71 & 0.586 \\
\hline Diabetes (yes versus no) & 0.61 & 0.33 to 1.12 & 0.110 & 1.10 & 0.39 to 3.08 & 0.854 \\
\hline Smoking (never versus ever) & 1.63 & 0.86 to 3.11 & 0.136 & 1.15 & 0.54 to 2.41 & 0.720 \\
\hline Vitamin D levels (summer) ${ }^{a}$ & 1.16 & 0.60 to 2.25 & 0.663 & 1.25 & 0.55 to 2.86 & 0.591 \\
\hline Vitamin D levels (winter) $^{a}$ & 1.68 & 1.05 to 2.69 & 0.029 & 1.23 & 0.74 to 2.06 & 0.425 \\
\hline Season (winter versus summer) ${ }^{b}$ & 1.36 & 0.49 to 3.75 & 0.553 & 0.61 & 0.20 to 1.86 & 0.385 \\
\hline
\end{tabular}

Abbreviations: OR odds ratio, $\mathrm{Cl}$ confidence interval.

athird versus first quartile; sepsis cohort: 58.9 versus $27.6 \mathrm{nmol} / \mathrm{L}$; trauma cohort: 71.9 versus $37.2 \mathrm{nmol} / \mathrm{L}$.

bitamin D was fixed at median; sepsis cohort: $43.2 \mathrm{nmol} / \mathrm{L}$; trauma cohort: $53.4 \mathrm{nmol} / \mathrm{L}$.

1.01 to 1.08$),(P=0.02)$ and 1.06 (95\% CI 1.04 to 1.08 , $P<0.001)$ respectively. All other variables had no significant association with hospital or one-year mortality in our models.

\section{Discussion}

In this case-control study of two 'at risk' populations for ALI/ARDS, patients with severe sepsis or severe trauma, vitamin $\mathrm{D}$ levels measured on the morning after ICU admission were not associated with development of ALI/ ARDS. Furthermore, in a stratified analysis of patients with sepsis during the winter season, higher rather than lower vitamin $\mathrm{D}$ levels were associated with increased risk for ALI/ARDS $(P=0.03)$. The biologic rationale for this finding is uncertain. One potential explanation is that vitamin D physiology is complex. Higher vitamin D levels may, in certain situations, paradoxically increase the pathogen burden [39] leading to a worsening of proinflammatory stress in the lung and thence to ALI/ ARDS. Another, more likely, interpretation for our primary findings is that low levels of vitamin $D$ are not associated with development of ALI/ARDS and are potentially epiphenomena of severity and/or chronicity of illness [40]. In the current study, when cases and controls were rigorously matched for severity of illness using APACHE II scores and other clinical characteristics, no association between ALI/ARDS and 25-OHD levels was apparent. This result was consistent across two diverse patient groups and risk factors for ALI/ ARDS: severe sepsis and severe trauma.

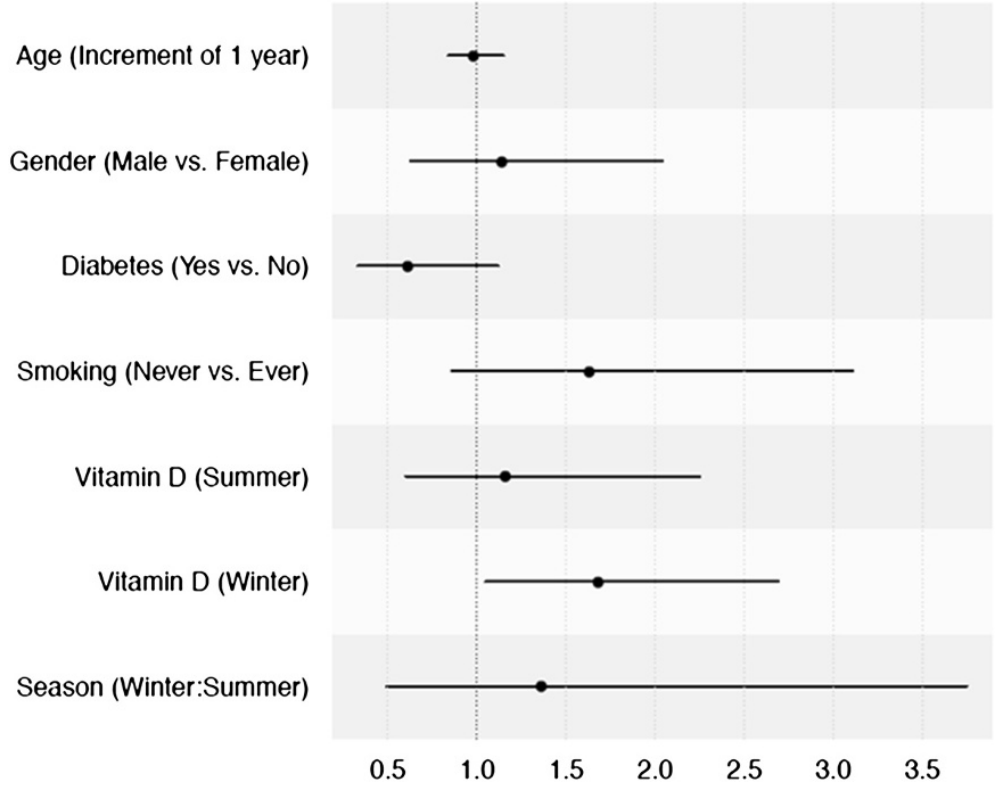

Figure 2 Forest plot summary of logistic regression analysis for risk of acute lung injury/acute respiratory distress syndrome (ALI/ARDS) in the sepsis cohort. Higher vitamin D levels in winter were associated with a higher odds ratio (OR) for developing ALI/ARDS: OR 1.68 (95\% CI 1.054 to 2.69), ( $P=0.03)$. OR (black dots) and the corresponding Cls (black lines) for the risk of ALI/ARDS for each covariate are shown. 
Table 3 Survival analysis for hospital mortality in the sepsis cohort (left) and the trauma cohort (right)

\begin{tabular}{|c|c|c|c|c|c|c|}
\hline \multirow[t]{2}{*}{ Characteristics } & \multicolumn{3}{|c|}{ Sepsis cohort } & \multicolumn{3}{|c|}{ Trauma cohort } \\
\hline & HR & $95 \% \mathrm{Cl}$ & $P$-value & HR & $95 \% \mathrm{Cl}$ & $P$-value \\
\hline Age (increment of one year) & 1.02 & 1.00 to 1.05 & 0.100 & 1.04 & 1.01 to 1.08 & 0.019 \\
\hline Gender (male versus female) & 1.19 & 0.67 to 2.12 & 0.552 & 1.16 & 0.37 to 3.62 & 0.794 \\
\hline Diabetes (yes versus no) & 1.14 & 0.64 to 2.02 & 0.663 & 0.82 & 0.22 to 3.05 & 0.768 \\
\hline Smoking (never versus ever) & 0.82 & 0.44 to 1.54 & 0.543 & 0.90 & 0.31 to 2.66 & 0.855 \\
\hline Vitamin D levels $^{\mathrm{a}}$ & 0.74 & 0.53 to 1.05 & 0.092 & 0.59 & 0.30 to 1.19 & 0.140 \\
\hline Season (winter versus summer) & 0.86 & 0.48 to 1.54 & 0.618 & 0.85 & 0.27 to 2.73 & 0.787 \\
\hline
\end{tabular}

Abbreviations: HR hazard ratio, $\mathrm{Cl}$ confidence interval.

athird versus first quartile; sepsis cohort: 58.9 versus $27.6 \mathrm{nmol} / \mathrm{L}$; trauma cohort: 71.9 versus $37.2 \mathrm{nmol} / \mathrm{L}$.

Experimental evidence for the deleterious effects of vitamin $\mathrm{D}$ deficiency on organ and immune dysfunction abounds $[13,41]$ but evidence in the intensive care arena is lacking. Jeng et al. [19] found that both septic and nonseptic ICU patients had low vitamin D levels without any demonstrable differences in levels between groups suggesting that critical illness per se is preceded by or results in low vitamin D levels. On the other hand, Braun et al. [22] in a much larger 2,399 patient cohort provide evidence for an association of vitamin D deficiency with mortality in the ICU. They showed an association of ICU, hospital, 30, 60, 90 and 365-day mortality in patients with the lowest levels of pre-admission (up to one year prior to admission) vitamin D levels. A subsequent study by the same group [23] examined peri-admission (seven days prior to and/or seven days following ICU admission) 25OHD levels, and likewise reported a positive association between 25-OHD deficiency and 30-day mortality. Secondary end-points of 90 and 365-day mortality also were associated with peri-admission vitamin D deficiency.

In this study, sepsis patients with increased vitamin D levels demonstrated a non-significant trend to reduced hospital mortality $(P=0.09)$ that did not persist to oneyear $(P=0.24)$. By comparison, Braun et al. [22] obtained 25-OHD samples up to a year prior to ICU admission potentially deterring from their predictive power at the time of critical illness. To dispel this limitation a follow-up study [23] examined 25-OHD levels around the time of critical care initiation and observed a similar association.
However, the time span from measurement to critical care initiation was relatively large (14 days) as opposed to the narrower 36 hours defined in our study. Moreover, neither analysis included information on important co-variates that may affect 25-OHD levels such as smoking or aggregate scores of chronic disease and physiologic perturbation such as APACHE II score that may affect mortality risk [30]. In the current study we elected to control for severity of illness because it is likely to impact negatively both on vitamin $\mathrm{D}$ levels and mortality. In many patients, relative malnutrition and periods of physical inactivity precede critical illness. Second, a dilutional effect may occur owing to vigorous fluid resuscitation at the time of critical illness [42]. While we did not control for volume of resuscitation in our analysis, matching by severity of illness (APACHE II or ISS scores) should imply a similar resuscitation burden between and across cohorts, thereby minimizing the potentially confounding effects of acute fluid loading.

Interestingly, lower 25-OHD levels were significantly associated with one-year mortality $(P<0.001)$ in trauma patients, the first time this association has been observed. Very little has been published regarding long term outcomes from major trauma. A recent study implicated age older than 65, hospitalization greater than 28 days and unintentional falls as risk factors for delayed one-year mortality following trauma [43]. Our data also identified older age to be a significant risk factor for delayed mortality after trauma (Table 4). Older age and unintentional falls

Table 4 Survival analysis for delayed, one-year mortality in the sepsis cohort (left) and the trauma cohort (right)

\begin{tabular}{|c|c|c|c|c|c|c|}
\hline \multirow[t]{2}{*}{ Characteristics } & \multicolumn{3}{|c|}{ Sepsis cohort } & \multicolumn{3}{|c|}{ Trauma cohort } \\
\hline & $\overline{\mathrm{HR}}$ & $95 \% \mathrm{Cl}$ & $P$-value & $\overline{H R}$ & $95 \% \mathrm{Cl}$ & $P$-value \\
\hline Age (increment of one year) & 1.02 & 1.00 to 1.04 & 0.023 & 1.06 & 1.04 to 1.08 & 0.023 \\
\hline Gender (male versus female) & 1.26 & 0.90 to 1.78 & 0.181 & 2.04 & 1.00 to 4.18 & 0.051 \\
\hline Diabetes (yes versus no) & 1.04 & 0.72 to 1.49 & 0.841 & 0.63 & 0.28 to 1.45 & 0.280 \\
\hline Apache II/ISS score ${ }^{b}$ & 1.35 & 1.05 to 1.73 & 0.019 & 1.04 & 0.68 to 1.60 & 0.849 \\
\hline Vitamin D levels (high versus low) ${ }^{a}$ & 0.87 & 0.68 to 1.10 & 0.240 & 0.50 & 0.35 to 0.72 & $<0.001$ \\
\hline
\end{tabular}

Abbreviations: $\mathrm{HR}$ hazard ratio, $\mathrm{Cl}$ confidence interval.

${ }^{a}$ third versus first quartile; sepsis cohort: 58.9 versus $27.6 \mathrm{nmol} / \mathrm{L}$; trauma cohort: 71.9 versus $37.2 \mathrm{nmol} / \mathrm{L}$

${ }^{b}$ third versus first quartile; sepsis cohort: Apache II score, 32.2 versus 23; trauma cohort: ISS score, 36.0 versus 23.5 . 
Table 5 Basline characteristics of patients from the trauma cohort

\begin{tabular}{|c|c|c|c|c|c|}
\hline Characteristic & $\mathrm{N}$ & $\begin{array}{l}\text { Cases } \\
(n=119)\end{array}$ & $\begin{array}{l}\text { Controls } \\
(n=119)\end{array}$ & $\begin{array}{l}\text { Combined } \\
(\mathrm{n}=238)\end{array}$ & $P$-value \\
\hline $\mathrm{Age}^{c}$ & 238 & $44.7(30.8,58.2)$ & $46.8(29.8,56.8)$ & $46.2(30.4,57.8)$ & $0.651^{a}$ \\
\hline Female gender (\%) & 238 & $35(29)$ & $33(28)$ & $68(29)$ & $0.883^{b}$ \\
\hline Smoking (\%) & 194 & & & & $0.370^{b}$ \\
\hline Never & & $36(35)$ & $30(33)$ & $66(34)$ & \\
\hline Former & & $8(8)$ & $3(3)$ & $11(6)$ & \\
\hline Current & & $60(58)$ & $57(63)$ & $117(60)$ & \\
\hline Diabetes (\%) & 238 & $16(13)$ & $16(13)$ & $32(13)$ & $1^{b}$ \\
\hline Summer season (\%) & 238 & $48(40)$ & $48(40)$ & $96(40)$ & $1^{b}$ \\
\hline Day length hours $(\mathrm{IQR})^{\mathrm{c}}$ & 238 & $12.6(10.8,13.8)$ & $12.6(10.7,13.9)$ & $12.6(10.8,13.9)$ & $0.331^{a}$ \\
\hline APACHE II score (IQR) & 238 & $26.0(21.5,29.5)$ & $24.0(19.0,27.5)$ & $25.0(20.0,29.0)$ & $0.078^{a}$ \\
\hline$\overline{I S S^{C}(I Q R)}$ & 204 & $29.0(24.0,35.8)$ & $29.0(22.0,36.0)$ & $29.0(23.5,36.0)$ & $0.993^{a}$ \\
\hline Number of non-pulmonary organ failures (\%) & 238 & & & & $0.645^{a}$ \\
\hline 0 & & $42(35)$ & $49(41)$ & $91(38)$ & \\
\hline 1 & & $61(51)$ & $52(44)$ & $113(47)$ & \\
\hline 2 & & $13(11)$ & $15(13)$ & $28(12)$ & \\
\hline 3 & & $3(3)$ & $3(3)$ & $6(3)$ & \\
\hline Days of ICU stay (IQR) & 238 & $11.0(7.0,18.5)$ & $9.0(5.0,16.0)$ & $10.0(6.0,18.0)$ & $0.155^{\mathrm{a}}$ \\
\hline Hospital mortality (\%) & 238 & $10(8)$ & $13(11)$ & $23(10)$ & $0.663^{b}$ \\
\hline One-year mortality (\%) & 238 & $20(17)$ & $25(21)$ & $45(19)$ & $0.511^{b}$ \\
\hline Risk factors for ALI/ARDS & 235 & & & & \\
\hline Severe trauma & & $116(99)$ & $116(99)$ & $232(99)$ & \\
\hline Aspiration & & $2(2)$ & $0(0)$ & $2(1)$ & \\
\hline Other or None ${ }^{d}$ & & $0(0)$ & $1(1)$ & $1(1)$ & \\
\hline Patients on ventilator & & $115(97)$ & $115(97)$ & $230(97)$ & $1^{b}$ \\
\hline 25-OHD (nmol/L) (IQR) & 237 & $54.9(38.3,72.5)$ & $50.8(36.9,69.8)$ & $53.4(37.2,71.9)$ & $0.302^{a}$ \\
\hline Vitamin D Status (\%) & 237 & & & & $0.606^{b}$ \\
\hline Deficiency $(<50 \mathrm{nmol} / \mathrm{L})$ & & $54(45)$ & $59(50)$ & $113(48)$ & \\
\hline Insufficiency (50 to $75 \mathrm{nmol} / \mathrm{L}$ ) & & $37(31)$ & $38(32)$ & $75(32)$ & \\
\hline Sufficiency (> $75 \mathrm{nmol} / \mathrm{L})$ & & $28(24)$ & $21(18)$ & $49(21)$ & \\
\hline
\end{tabular}

Data given as median and interquartile range (IQR) or frequency with (\%) of patients.

$\mathrm{N}$ is the number of non-missing values.

${ }^{\mathrm{a}}$ Wilcoxon signed rank test; ${ }^{\mathrm{b}} \mathrm{McNemar}$ 's test; ${ }^{\mathrm{C}}$ Matched; ${ }^{\mathrm{d}}$ Other or None (multiple transfusions).

could plausibly be biologically linked to lower 25-OHD levels though the potential for residual confounding remains. For example, confounding by BMI, for which we do not have data in our study, is a possible explanation for this result. A higher BMI correlates both with worse outcomes [44] from trauma and is associated with lower 25-OHD levels [45]. However, cases and controls for this study were matched with our primary end-point (ALI/ARDS) in mind and not mortality and as such this result is a novel and potentially hypothesis-generating observation.

The study has some limitations. Study design allowed us to control for severity of illness but the study was not powered for mortality analysis and the case-control design may limit the generalizability of the findings. A second limitation is that we did not measure serial vitamin D levels and therefore could not correlate vitamin D kinetics during critical illness to acute decompensations or improvements in clinical status. Higgins et al. [46] recently showed a mean reduction in 25-OHD levels during critical illness of $2.6 \mathrm{mmol} / \mathrm{L}$ by day three and $6.0 \mathrm{mmol} / \mathrm{L}$ by day ten. Reid et al. [47] similarly observed a mean diminution of $2.7 \mathrm{mmol} / \mathrm{L}$ in 25-OHD levels 48 hours after an acute surgical insult for elective hip or knee surgery together with a mean reciprocal increase in CRP from 5 to $116 \mathrm{mg} / \mathrm{ml} \mathrm{-} \mathrm{a} \mathrm{situation} \mathrm{that}$ may pertain to all fat-soluble vitamins [48]. They conclude that 25-OHD is likely a negative acute phase reactant with low levels persisting for several months after an inflammatory insult. 


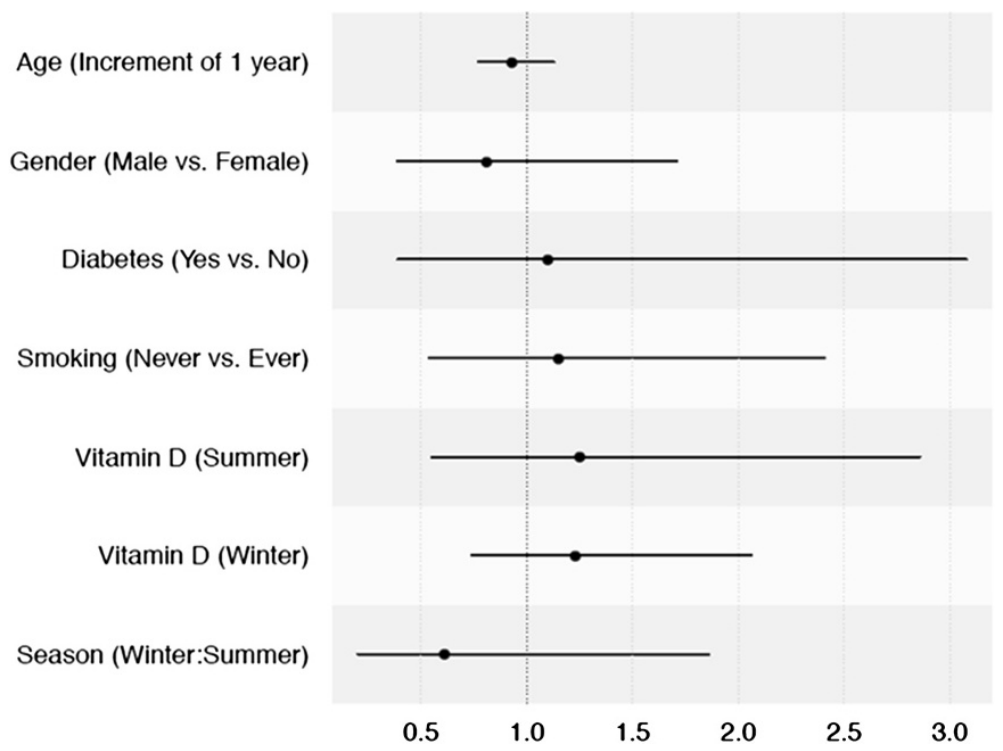

Figure 3 Forest plot of logistic regression analysis for risk of acute lung injury/acute respiratory distress syndrome (ALI/ARDS) in the trauma cohort. Vitamin D levels were not associated with risk of ALI/ARDS in severe trauma. Odds ratio (black dots) and the corresponding confidence intervals (black lines) for the risk of ALI/ARDS for each covariate are shown.

A third potential limitation is that we were unable to control for vitamin D binding protein (VDBP). Falls in this protein during critical illness could impact on 25OHD levels. However, the association of vitamin D with its binding protein is complex [49] and non-linear. Furthermore, higher levels of VDBP may limit the bioavailability of the free and bioactive vitamin [50]. Because of this complexity, future studies of vitamin D deficiency and outcomes in ICU may wish to measure both serial vitamin D levels and VDBP.

Additionally, we were also unable to control for prehospital use of calcium and vitamin $\mathrm{D}$ that could be a potential confounder of serum 25-OHD levels. However, this information can be difficult to obtain even prospectively in critically ill patients and hence is absent from the majority of studies of vitamin $\mathrm{D}$ in critical illness $[19,22,23]$. We have found only one small study with information on calcium/vitamin D supplementation [38]. In this study, only $13 \%$ of the total cohort was on supplements but $7 \%$ had end-stage renal failure, a patient group commonly on supplementation. Moreover, supplementation in this study was predictive of vitamin D deficiency supporting the hypothesis that most patients on supplements had concomitant renal failure with hypovitaminosis D. In addition, with a median age in the mid 40s, it is unlikely that patients in our trauma cohort were on vitamin D supplementation. Finally, we did not obtain data and, therefore, could not control for transfusion requirements, which may influence ARDS risk [51] and potentially be associated with vitamin D levels. There is however no evidence on the stability of fat- soluble vitamins in transfused blood and matching by trauma severity (ISS) would plausibly suggest similar transfusion schedules.

Our study has several strengths. To our knowledge, it is the first study to investigate the association of ALI/ ARDS in critical illness with 25-OHD levels. We report a consistent lack of association between lower 25-OHD levels and risk of ALI/ARDS across two cohorts of patients who were carefully matched for age, gender, smoking status and severity of illness with distinct risks for ALI/ARDS. Both cohorts mirror each other in suggesting that patients with ALI/ARDS have slightly elevated 25-OHD levels in comparison to their control counterparts lending internal validity to the findings. The study population is broad, rigorously phenotyped and representative of a critical care population in terms of disease acuity (based on APACHE II and ISS scores), basic demographics, the spectrum of ICUs (cardiac, medical, surgical and trauma) and hospital mortality across both cohorts. Furthermore, blood was sampled at clear and uniform time-points, early in the course of critical illness allowing for a consistent analysis of the relationship between the exposure, 25-OHD levels, and the outcome of interest, ALI/ARDS.

Although the findings of this study are not definitive, they do call into question the hypothesis that vitamin D supplementation might help reconstitute immune, endothelial, epithelial and thence organ function across a variety of clinical and biological end-points [52]. Indeed, the Institute of Medicine's recent report [53] stated that there was insufficient evidence at present to recommend 
higher dietary intake of vitamin D other than for bone health. Prospective studies of supplementation in critical illness are awaited before any definitive conclusions can be drawn. However recent negative supplementation studies in respiratory $[54,55]$ and cardiovascular disease [56] tend to support the Institute of Medicine's position.

\section{Conclusions}

This case-control study of 478 patients with sepsis or trauma showed no association between lower 25-OHD levels and development of ALI/ARDS in stringently matched cases and controls. Contrary to our initial hypothesis, we noted the unexpected finding of higher 25-OHD levels associated with ALI/ARDS in winter in the sepsis cohort. In a secondary analysis, we discerned no associations between lower 25-OHD levels and hospital or delayed mortality with the exception of an association of higher 25OHD levels with a lower risk of one-year mortality from trauma. While the present study does not preclude a potential beneficial effect of vitamin D supplementation in severe sepsis, our findings suggest that any potential benefit is not likely to be related to prevention of ALI/ARDS; a hitherto unsuspected mortality benefit may, however, exist for patients with severe trauma.

\section{Additional file}

Additional file 1: Flow chart of patients in study.

\begin{abstract}
Abbreviations
25-OHD: 25-hydroxyvitamin D; ALI/ARDS: acute lung injury/acute respiratory distress syndrome; APACHE II: Acute Physiology and Chronic Health Evaluation; CLIA: competitive chemiluminescence immunoassay; ISS: Injury Severity Score; VALID: Validating Acute Lung Injury biomarkers for Diagnosis study; VDBP: vitamin D binding protein.
\end{abstract}

\section{Competing interests}

The authors declare that they have no competing interests.

\section{Authors' contributions}

NB designed the study, analyzed the data and wrote and edited the manuscript. ZZ and TK analyzed the data and edited the manuscript. DJ and CYW analyzed patient data and edited the manuscript. AM enrolled patients and edited the manuscript. GB designed the study and edited the manuscript. LW conceived and designed the study, analyzed data and edited the manuscript. All authors read and approved the final manuscript.

\section{Acknowledgements}

This work was supported by UL1 RR024975-01 from NCRR/NIH, HL103836 and HL088263 from the NIH and an American Heart Association Established Investigator Award.

\section{Author details}

'Division of Allergy, Pulmonary and Critical Care Medicine in the Department of Medicine, Vanderbilt University, T1218 MCN, 1161 21st Avenue South, Nashville, TN, USA. ²Department of Biostatistics, Vanderbilt University, Nashville, TN, USA. ${ }^{3}$ Division of Trauma and Surgical Critical Care, Department of Surgery, Vanderbilt University Medical Center, Nashville, TN, USA. ${ }^{4}$ Division of Internal Medicine Taichung Veterans General Hospital, Taichung, Taiwan. ${ }^{5}$ Department of Pathology, Microbiology and Immunology, Vanderbilt University, Nashville, TN, USA.
Received: 17 September 2013 Accepted: 13 February 2014

Published: 24 February 2014

\section{References}

1. Peterlik M, Grant WB, Cross HS: Calcium, vitamin D and cancer. Anticancer Res 2009, 29(9):3687-3698.

2. Giovannucci E, Liu Y, Hollis BW, Rimm EB: 25-hydroxyvitamin D and risk of myocardial infarction in men: a prospective study. Arch Intern Med 2008, 168(11):1174-1180.

3. Takiishi T, Gysemans C, Bouillon R, Mathieu C: Vitamin D and diabetes. Endocrinol Metab Clin North Am 2010, 39(2):419-446.

4. Searing DA, Leung DY: Vitamin D in atopic dermatitis, asthma and allergic diseases. Immunol Allergy Clin North Am 2010, 30(3):397-409.

5. Pelajo CF, Lopez-Benitez JM, Miller LC: Vitamin D and autoimmune rheumatologic disorders. Autoimmun Rev 2010, 9(7):507-510.

6. Nnoaham KE, Clarke A: Low serum vitamin D levels and tuberculosis: a systematic review and meta-analysis. Int J Epidemiol 2008, 37(1):113-119.

7. Mirkovic K, van den Born J, Navis G, de Borst MH: Vitamin D in chronic kidney disease: new potential for intervention. Curr Drug Targets 2011, 12(1):42-53.

8. Ginde AA, Mansbach JM, Camargo CA Jr: Association between serum 25-hydroxyvitamin $D$ level and upper respiratory tract infection in the third national health and nutrition examination survey. Arch Intern Med 2009, 169(4):384-390.

9. Deluca HF, Cantorna MT: Vitamin D: its role and uses in immunology. FASEB J 2001, 15(14):2579-2585.

10. Autier P, Gandini S: Vitamin D supplementation and total mortality: a meta-analysis of randomized controlled trials. Arch Intern Med 2007, 167(16):1730-1737

11. Bjelakovic G, Gluud LL, Nikolova D, Whitfield K, Wetterslev J, Simonetti RG, Bjelakovic M, Gluud C: Vitamin D supplementation for prevention of mortality in adults. Cochrane Database Syst Rev 2011, 7, CD007470.

12. Sadeghi K, Wessner B, Laggner U, Ploder M, Tamandl D, Friedl J, Zugel U, Steinmeyer A, Pollak A, Roth E, Boltz-Nitulescu G, Spittler A: Vitamin D3 down-regulates monocyte TLR expression and triggers hyporesponsiveness to pathogen-associated molecular patterns. Eur J Immunol 2006, 36(2):361-370.

13. Kong J, Zhang Z, Musch MW, Ning G, Sun J, Hart J, Bissonnette M, Li YC: Novel role of the vitamin $D$ receptor in maintaining the integrity of the intestinal mucosal barrier. Am J Physiol Gastrointest Liver Physiol 2008, 294(1):G208-G216

14. Liu PT, Stenger S, Li H, Wenzel L, Tan BH, Krutzik SR, Ochoa MT, Schauber J, Wu K, Meinken C, Kamen DL, Wagner M, Bals R, Steinmeyer A, Zügel U, Gallo RL, Eisenberg D, Hewison M, Hollis BW, Adams JS, Bloom BR, Modlin RL: Toll-like receptor triggering of a vitamin D-mediated human antimicrobial response. Science 2006, 311(5768):1770-1773.

15. Lagishetty V, Misharin AV, Liu NQ, Lisse TS, Chun RF, Ouyang Y, McLachlan SM, Adams JS, Hewison M: Vitamin D deficiency in mice impairs colonic antibacterial activity and predisposes to colitis. Endocrinol 2010, 151(6):2423-2432.

16. Pistolic J, Cosseau C, Li Y, Yu JJ, Filewod NC, Gellatly S, Rehaume LM, Bowdish DM, Hancock RE: Host defence peptide LL-37 induces IL-6 expression in human bronchial epithelial cells by activation of the NF-kappaB signaling pathway. J Innate Immun 2009, 1(3):254-267.

17. Schauber J, Oda Y, Buchau AS, Yun QC, Steinmeyer A, Zugel U, Bikle DD, Gallo RL: Histone acetylation in keratinocytes enables control of the expression of cathelicidin and CD14 by 1,25-dihydroxyvitamin D3. $J$ Invest Dermatol 2008, 128(4):816-824.

18. Lee $P$, Eisman JA, Center JR: Vitamin D deficiency in critically ill patients. N Engl J Med 2009, 360(18):1912-1914.

19. Jeng L, Yamshchikov AV, Judd SE, Blumberg HM, Martin GS, Ziegler TR, Tangpricha $V$ : Alterations in vitamin D status and anti-microbial peptide levels in patients in the intensive care unit with sepsis. J Trans/ Med 2009, 7:28.

20. McKinney JD, Bailey BA, Garrett LH, Peiris P, Manning T, Peiris AN: Relationship between vitamin D status and ICU outcomes in veterans. J Am Med Dir Assoc 2011, 12(3):208-211.

21. Venkatram S, Chilimuri S, Adrish M, Salako A, Patel M, Diaz-Fuentes G: Vitamin D deficiency as associated with mortality in the medical intensive care unit. Crit Care 2011, 15(6):R292. 
22. Braun A, Chang D, Mahadevappa K, Gibbons FK, Liu Y, Giovannucci E, Christopher KB: Association of low serum 25-hydroxyvitamin D levels and mortality in the critically ill*. Crit Care Med 2011, 39(4):671-677.

23. Braun AB, Gibbons FK, Litonjua AA, Giovannucci E, Christopher KB: Low serum 25-hydroxyvitamin $D$ at critical care initiation is associated with increased mortality*. Crit Care Med 2012, 40(1):63-72.

24. Ware LB, Matthay MA: The acute respiratory distress syndrome. N Eng/ J Med 2000, 342(18):1334-1349.

25. Matthay MA, Ware LB, Zimmerman GA: The acute respiratory distress syndrome. J Clin Invest 2012, 122(8):2731-2740.

26. van Etten $E$, Mathieu C: Immunoregulation by 1,25-dihydroxyvitamin D3: basic concepts. J Steroid Biochem Mol Biol 2005, 97(1-2):93-101.

27. Al Mheid I, Patel R, Murrow J, Morris A, Rahman A, Fike L, Kavtaradze N, Uphoff I, Hooper C, Tangpricha V, Alexander RW, Brigham K, Quyyumi AA: Vitamin D status is associated with arterial stiffness and vascular dysfunction in healthy humans. J Am Coll Cardio/ 2011, 58(2):186-192.

28. O'Neal HR Jr, Koyama T, Koehler EA, Siew E, Curtis BR, Fremont RD, May AK Bernard GR, Ware LB: Prehospital statin and aspirin use and the prevalence of severe sepsis and acute lung injury/acute respiratory distress syndrome. Crit Care Med 2011, 39(6):1343-1350.

29. Siew ED, Ware LB, Gebretsadik T, Shintani A, Moons KG, Wickersham N, Bossert F, Ikizler TA: Urine neutrophil gelatinase-associated lipocalin moderately predicts acute kidney injury in critically ill adults. J Am Soc Nephrol 2009, 20(8):1823-1832.

30. Knaus WA, Draper EA, Wagner DP, Zimmerman JE: APACHE II: a severity of disease classification system. Crit Care Med 1985, 13(10):818-829.

31. Baker SP, O'Neill B, Haddon W Jr, Long WB: The injury severity score: a method for describing patients with multiple injuries and evaluating emergency care. J Trauma 1974, 14(3):187-196.

32. Levy MM, Fink MP, Marshall JC, Abraham E, Angus D, Cook D, Cohen J, Opal SM, Vincent JL, Ramsay G: 2001 SCCM/ESICM/ACCP/ATS/SIS International Sepsis Definitions Conference. Crit Care Med 2003, 31(4):1250-1256.

33. Bernard G: The Brussels score. Sepsis 1997, 1(1):43-44.

34. Bernard GR, Artigas A, Brigham KL, Carlet J, Falke K, Hudson L, Lamy M, Legall JR, Morris A, Spragg R: The American-European Consensus Conference on ARDS. Definitions, mechanisms, relevant outcomes, and clinical trial coordination. Am J Respir Crit Care Med 1994, 149(3 Pt 1):818-824.

35. Gallicchio L, Helzlsouer KJ, Chow WH, Freedman DM, Hankinson SE, Hartge P, Hartmuller V, Harvey C, Hayes RB, Horst RL, Koenig KL, Kolonel LN, Laden F, McCullough ML, Parisi D, Purdue MP, Shu X-O, Snyder K, StolzenbergSolomon RZ, Tworoger SS, Varanasi A, Virtamo J, Wilkens LR, Xiang Y-B, Yu K, Zeleniuch-Jacquotte A, Zheng W, Abnet CC, Albanes D, Bertrand K, et al: Circulating 25-hydroxyvitamin $\mathrm{D}$ and the risk of rarer cancers: design and methods of the cohort consortium vitamin $D$ pooling project of rarer cancers. Am J Epidemiol 2010, 172(1):10-20.

36. Horst RL: Exogenous versus endogenous recovery of 25-hydroxyvitamins D2 and D3 in human samples using high-performance liquid chromatography and the DiaSorin LIAISON Total-D Assay. J Steroid Biochem Mol Biol 2010, 121(1-2):180-182.

37. Holick MF: Vitamin D deficiency. N Engl J Med 2007, 357(3):266-281.

38. Lucidarme O, Messai E, Mazzoni T, Arcade M, du Cheyron D: Incidence and risk factors of vitamin $D$ deficiency in critically ill patients: results from a prospective observational study. Intensive Care Med 2010, 36(6):1609-1611.

39. Ryz NR, Patterson SJ, Zhang Y, Ma C, Huang T, Bhinder G, Wu X, Chan J, Glesby A, Sham HP, Dutz JP, Leving MK, Jacobson K, Vallance BA: Active vitamin $D(1,25$-dihydroxyvitamin D3) increases host susceptibility to Citrobacter rodentium by suppressing mucosal Th17 responses. Am J Physiol Gastrointest Liver Physiol 2012, 303(12):G1299-G1311.

40. Gama R, Waldron JL, Ashby HL, Cornes MP, Bechervaise J, Razavi C, Thomas OL, Chugh S, Deshpande S, Ford C: Hypovitaminosis D and disease: consequence rather than cause? BMJ 2012, 345:e5706.

41. Tan $X$, Wen $X$, Liu Y: Paricalcitol inhibits renal inflammation by promoting vitamin $D$ receptor-mediated sequestration of NF-kappaB signaling. J Am Soc Nephrol 2008, 19(9):1741-1752.

42. Krishnan A, Ochola J, Mundy J, Jones M, Kruger P, Duncan E, Venkatesh B: Acute fluid shifts influence the assessment of serum vitamin $D$ status in critically ill patients. Crit Care 2010, 14(6):R216.

43. Laupland KB, Svenson LW, Grant V, Ball CG, Mercado M, Kirkpatrick AW: Long-term mortality outcome of victims of major trauma. Injury 2010 , 41(1):69-72.
44. Hoffmann M, Lefering R, Gruber-Rathmann M, Rueger JM, Lehmann W: The impact of BMI on polytrauma outcome. Injury 2012, 43(2):184-188.

45. McCullough ML, Weinstein SJ, Freedman DM, Helzlsouer K, Flanders WD, Koenig K, Kolonel L, Laden F, Le Marchand L, Purdue M, Snyder K, Stevens VL, Stolzenberg-Solomon R, Virtamo J, Yang G, Yu K, Zheng W, Albanes D, Ashby J, Bertrand K, Cai H, Chen Y, Gallicchio L, Giovannucci E, Jacobs EJ, Hankinson SE, Hartge P, Hartmuller V, Harvey C, Hayes RB, et al: Correlates of circulating 25-hydroxyvitamin D: cohort consortium vitamin D pooling project of rarer cancers. Am J Epidemiol 2010, 172(1):21-35.

46. Higgins DM, Wischmeyer PE, Queensland KM, Sillau SH, Sufit AJ, Heyland DK: Relationship of vitamin D deficiency to clinical outcomes in critically III patients. JPEN J Parenter Enteral Nutr 2012, 36(6):713-720.

47. Reid D, Toole BJ, Knox S, Talwar D, Harten J, O'Reilly DS, Blackwell S, Kinsella J, McMillan DC, Wallace AM: The relation between acute changes in the systemic inflammatory response and plasma 25 -hydroxyvitamin D concentrations after elective knee arthroplasty. Am J Clin Nutr 2011, 93(5):1006-1011.

48. Louw JA, Werbeck A, Louw ME, Kotze TJ, Cooper R, Labadarios D: Blood vitamin concentrations during the acute-phase response. Crit Care Med 1992, 20(7):934-941.

49. Van den Berghe G, Van Roosbroeck D, Vanhove P, Wouters PJ, De Pourca L, Bouillon R: Bone turnover in prolonged critical illness: effect of vitamin D. J Clin Endocrinol Metab 2003, 88(10):4623-4632.

50. Chun RF, Lauridsen AL, Suon L, Zella LA, Pike JW, Modlin RL, Martineau AR, Wilkinson RJ, Adams J, Hewison M: Vitamin D-binding protein directs monocyte responses to 25-hydroxy- and 1,25-dihydroxyvitamin D. J Clin Endocrinol Metab 2010, 95(7):3368-3376.

51. Miller PR, Croce MA, Kilgo PD, Scott J, Fabian TC: Acute respiratory distress syndrome in blunt trauma: identification of independent risk factors. Am Surg 2002, 68(10):845-850. Discussion 850-841.

52. Lee $P$, Nair $P$, Eisman JA, Center JR: Vitamin D deficiency in the intensive care unit: an invisible accomplice to morbidity and mortality? Intensive Care Med 2009, 35(12):2028-2032.

53. Institute of Medicine: Dietary Reference Intakes for Calcium and Vitamin D. Washington, DC: National Academies Press; 2011.

54. Wejse C, Gomes VF, Rabna P, Gustafson P, Aaby P, Lisse IM, Andersen PL, Glerup H, Sodemann M: Vitamin D as supplementary treatment for tuberculosis: a double-blind, randomized, placebo-controlled trial. Am J Respir Crit Care Med 2009, 179(9):843-850.

55. Manaseki-Holland S, Maroof Z, Bruce J, Mughal MZ, Masher MI, Bhutta ZA, Walraven G, Chandramohan D: Effect on the incidence of pneumonia of vitamin D supplementation by quarterly bolus dose to infants in Kabul: a randomised controlled superiority trial. Lancet 2012, 379(9824):1419-1427.

56. Sokol SI, Srinivas V, Crandall JP, Kim M, Tellides G, Lebastchi A, Yu Y, Gupta AK, Alderman MH: The effects of vitamin D repletion on endothelial function and inflammation in patients with coronary artery disease. Vasc Med 2012, 17(6):394-404.

\section{doi:10.1186/2110-5820-4-5}

Cite this article as: Barnett et al:: Vitamin D deficiency and risk of acute lung injury in severe sepsis and severe trauma: a case-control study. Annals of Intensive Care 2014 4:5.

\section{Submit your manuscript to a SpringerOpen ${ }^{\circ}$ journal and benefit from:}

- Convenient online submission

- Rigorous peer review

- Immediate publication on acceptance

- Open access: articles freely available online

- High visibility within the field

- Retaining the copyright to your article

Submit your next manuscript at $>$ springeropen.com 